\title{
Poorly controlled postoperative pain: prevalence, consequences, and prevention
}

This article was published in the following Dove Press journal: Journal of Pain Research

25 September 2017

Number of times this article has been viewed

\section{Tong J Gan}

Stony Brook University, Stony Brook, NY, USA
Correspondence: Tong J Gan

Stony Brook University, 100 Nicolls

Road - HSC L4-060, Stony Brook, NY

II 794, USA

Tel + I 63| 4442975

Fax + I 63I 4442907

Email tong.gan@stonybrookmedicine.edu
Abstract: This review provides an overview of the clinical issue of poorly controlled postoperative pain and therapeutic approaches that may help to address this common unresolved health-care challenge. Postoperative pain is not adequately managed in greater than $80 \%$ of patients in the US, although rates vary depending on such factors as type of surgery performed, analgesic/anesthetic intervention used, and time elapsed after surgery. Poorly controlled acute postoperative pain is associated with increased morbidity, functional and quality-of-life impairment, delayed recovery time, prolonged duration of opioid use, and higher health-care costs. In addition, the presence and intensity of acute pain during or after surgery is predictive of the development of chronic pain. More effective analgesic/anesthetic measures in the perioperative period are needed to prevent the progression to persistent pain. Although clinical findings are inconsistent, some studies of local anesthetics and nonopioid analgesics have suggested potential benefits as preventive interventions. Conventional opioids remain the standard of care for the management of acute postoperative pain; however, the risk of opioid-related adverse events can limit optimal dosing for analgesia, leading to poorly controlled acute postoperative pain. Several new opioids have been developed that modulate $\mu$-receptor activity by selectively engaging intracellular pathways associated with analgesia and not those associated with adverse events, creating a wider therapeutic window than unselective conventional opioids. In clinical studies, oliceridine (TRV130), a novel $\mu$-receptor G-protein pathway-selective modulator, produced rapid postoperative analgesia with reduced prevalence of adverse events versus morphine.

Keywords: acute pain, chronic pain, surgical procedures, analgesics, opioid

\section{Introduction}

Surgery and anesthesia are critical health-care services that reduce the risk of death and disability among millions worldwide each year, and the need for these services is expected to continue to increase over the next decade. ${ }^{1}$ Globally, nearly 313 million operations were performed in $2012,{ }^{2}$ whereas in the US an estimated 28 million inpatient surgical procedures and 48 million ambulatory surgeries were reported in 2006 and 2010, respectively. ${ }^{3,4}$ Although possibly life-saving, surgery is also associated with potential harm, which frequently includes pain during and after the procedure. Despite improved understanding of pain mechanisms, increased awareness of the prevalence of postsurgical pain, advances in pain-management approaches, and other focused initiatives aimed at improving pain-related outcomes in recent decades, inadequately controlled postoperative pain continues to be a widespread, unresolved health-care problem. 
Suboptimal acute-pain management in surgery patients is accompanied by an array of negative consequences, including increased morbidity, impaired physical function and quality of life, slowed recovery, prolonged opioid use during and after hospitalization, and increased cost of care. In addition, early postoperative pain appears to trigger persistent pain that may last for months after surgery in a substantial proportion of patients. To prevent the progression from acute to chronic postoperative pain, more aggressive analgesic/anesthetic measures are needed to reduce the incidence and intensity of acute pain during and immediately after surgery. Although research on preventive interventions is limited, some promising results have been reported in studies of local anesthetics and nonopioid analgesics. ${ }^{5-7}$ In addition, a new class of opioid analgesics - selective agonists at the $\mu$-opioid receptor with a potentially expanded therapeutic window compared with conventional, unselective opioid therapies is currently in development. ${ }^{8-10}$ In early-phase studies, the $\mu$-receptor G-protein pathway-selective modulator oliceridine produced comparable but more rapid pain relief than morphine and fewer opioid-related adverse events (AEs), suggesting potential benefits in the prevention of postsurgical pain..$^{10,11}$
In this review, we examine the prevalence of poorly controlled acute postoperative pain and the major factors that may predict its occurrence. In addition, the consequences of inadequate pain management after surgery are described, with an emphasis on the potential development of chronic pain. Finally, we present findings from clinical studies of treatment approaches that may control acute postoperative pain more effectively, prevent its negative effects on patients' health, function, and quality of life, and reduce the risk of progression to persistent pain.

\section{Rates and risk factors of inadequately controlled acute postoperative pain}

According to the US Institute of Medicine, $80 \%$ of patients who undergo surgery report postoperative pain, with $88 \%$ of these patients reporting moderate, severe, or extreme pain levels. ${ }^{12}$ In a national US survey of 300 adults who had undergone surgery within the previous 5 years, $86 \%$ of patients experienced postsurgical pain overall, and $75 \%$ of those who reported pain described its severity as moderate-extreme during the immediate postoperative period (Figure 1). ${ }^{13}$

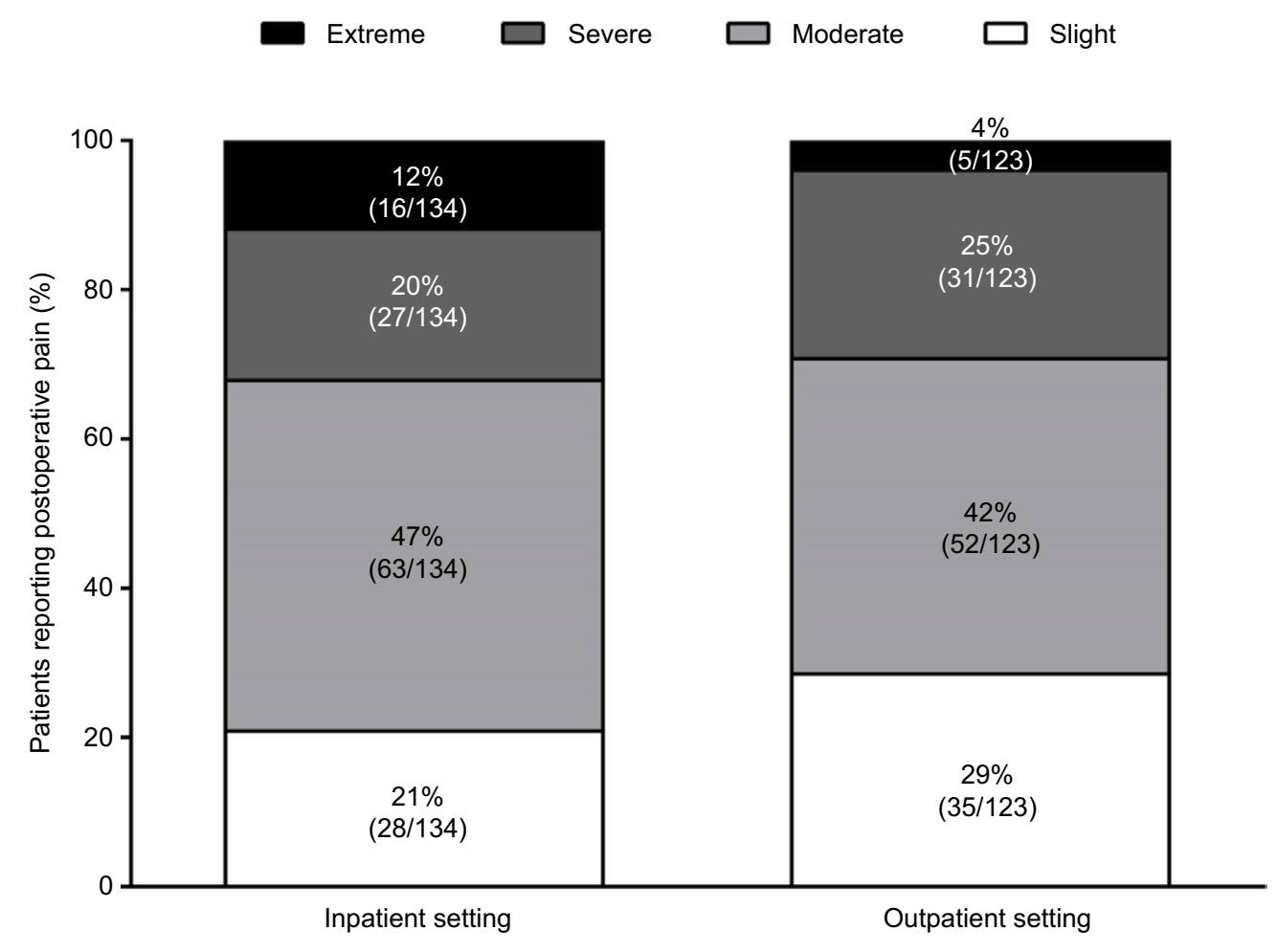

Patients reporting postoperative pain $\%$

$134 / 146(92 \%)$

$123 / 154(80 \%)$

Figure I Proportion of patients with postoperative pain in inpatient and outpatient settings by pain severity.

Note: Incidence, patient satisfaction, and perceptions of post-surgical pain: results from a US national survey. Gan TJ, Habib AS, Miller TE, White W, Apfelbaum JL.Current Medical Research and Opinion. Jan 2014. Reprinted by permission of the publisher (Taylor \& Francis Ltd, http://www.tandfonline.com). ${ }^{13}$ 
Acute pain has been commonly reported across many different surgery types, including both hard- and soft-tissue surgeries, despite administration of analgesic medication after surgery. ${ }^{13-19}$ Evidence from a prospective German cohort study of 50,523 patients from 179 surgical groups showed that pain scores on the first postoperative day were highest after obstetric and orthopedic/traumatic procedures, but scores were high after even common minor surgical procedures, such as appendectomy, cholecystectomy, hemorrhoidectomy, tonsillectomy, and some laparoscopic procedures. ${ }^{19}$ In a systematic literature review in which pain scores were pooled from 165 studies of acute pain following major surgery (abdominal, thoracic, orthopedic, and gynecological), in the first 24 hours after surgery, mean incidence of moderate-severe pain and severe pain was $30 \%$ and $11 \%$, respectively. ${ }^{20}$ The incidence of these pain levels varied by analgesic technique: lower incidence was reported with patient-controlled and epidural analgesia compared with intramuscular analgesia. ${ }^{20}$ In addition to the type of surgical procedure and analgesic/ anesthetic intervention, other predictive factors of the severity of acute postoperative pain include younger age, female sex, preoperative pain, anxiety/mood, and incision size. ${ }^{21-28}$ Finally, time after surgery also influences the frequency and severity of pain following surgery. In a Dutch study conducted in 1,490 surgical inpatients, $41 \%$ of patients reported moderate or severe pain on the day of surgery, with declining rates of $30 \%, 19 \%, 16 \%$, and $14 \%$ seen on postoperative days 1 , 2,3 , and 4 , respectively. ${ }^{17}$

\section{Consequences of acute postoperative pain}

Postoperative pain is not adequately managed in a significant proportion of patients, and is associated with a broad range of negative consequences, including increased morbidity, development of chronic postoperative pain, impaired function, recovery from surgery, and quality of life, prolonged opioid use, and increased medical costs.

\section{Morbidity}

Inadequately managed acute postoperative pain is associated with effects related to aspects of both physiological and psychological function. ${ }^{29-32}$ Changes can occur in diverse organ systems, including the cardiovascular (coronary ischemia, myocardial infarction), pulmonary (hypoventilation, decreased vital capacity, pulmonary infection), gastrointestinal (reduced motility, ileus, nausea, vomiting), and renal (increases in urinary retention and sphincter tone, oliguria) systems. A negative impact may also be seen on immune function, the muscular system, coagulation, and wound healing. Finally, poorly controlled pain after surgery may impair sleep and have negative psychological effects, such as demoralization and anxiety.

\section{Chronic postoperative pain}

Poorly managed acute pain experienced after surgery may also result in the development of chronic pain. Based on reviews of the literature, persistent pain appears to affect between $10 \%$ and $60 \%$ of patients after common operations. ${ }^{33-38}$ Fluctuations in reported incidence of chronic postsurgical pain are likely associated in part with the lack of a standardized definition of this complication, although it is frequently defined as enduring pain that has no other evident causes and lasts at least 2 months after surgery, ie, past the expected healing period..$^{33,34,39}$

As with early pain, the prevalence of chronic postsurgical pain varies by type of surgery and generally decreases with time. In a 2-year, Spanish prospective cohort study of 2,929 patients who required hernia repair, thoracotomy, or hysterectomy, the incidence of chronic pain ranged from 37.6\% (thoracotomy) to $11.8 \%$ (vaginal hysterectomy) at 4 months postsurgery (Figure 2). ${ }^{40}$ In a French prospective cohort study of 2,397 patients who underwent cholecystectomy, inguinal herniorrhaphy, saphenectomy, sternotomy, thoracotomy, knee arthroscopy, breast cancer surgery, or elective cesarean section, the highest mean pain scores were observed after knee arthroscopy and thoracotomy, and the lowest after herniorrhaphy and cesarean section. The proportions of patients who reported persistent pain were $34.8 \%$ and $29.5 \%$ at 3 and 6 months after surgery, respectively. ${ }^{41}$

Over the last two decades, understanding of the mechanisms involved in the development of chronic pain has improved, with a combination of factors emerging as contributors, most notably inflammatory processes, tissue and nerve damage, and central sensitization. ${ }^{26,42-44}$ The development of chronic pain after surgical intervention has been shown to involve preoperative, intraoperative, and postoperative factors. ${ }^{14,15,26,38,42,45-56}$ Numerous studies of patients undergoing a broad variety of surgery types have demonstrated that the presence and intensity of acute postoperative pain are significant predictive risk factors for the development of chronic pain (Table 1). ${ }^{14,15,26,38,45-53,55,57-75} \mathrm{~A}$ few studies have not found acute postoperative pain to be a significant predictor of chronic pain, but these conflicting findings may be linked to the studies' relatively small patient populations. ${ }^{46,54,76}$ Other potential determinants of persistent pain after surgery include younger age, female sex, obesity, 


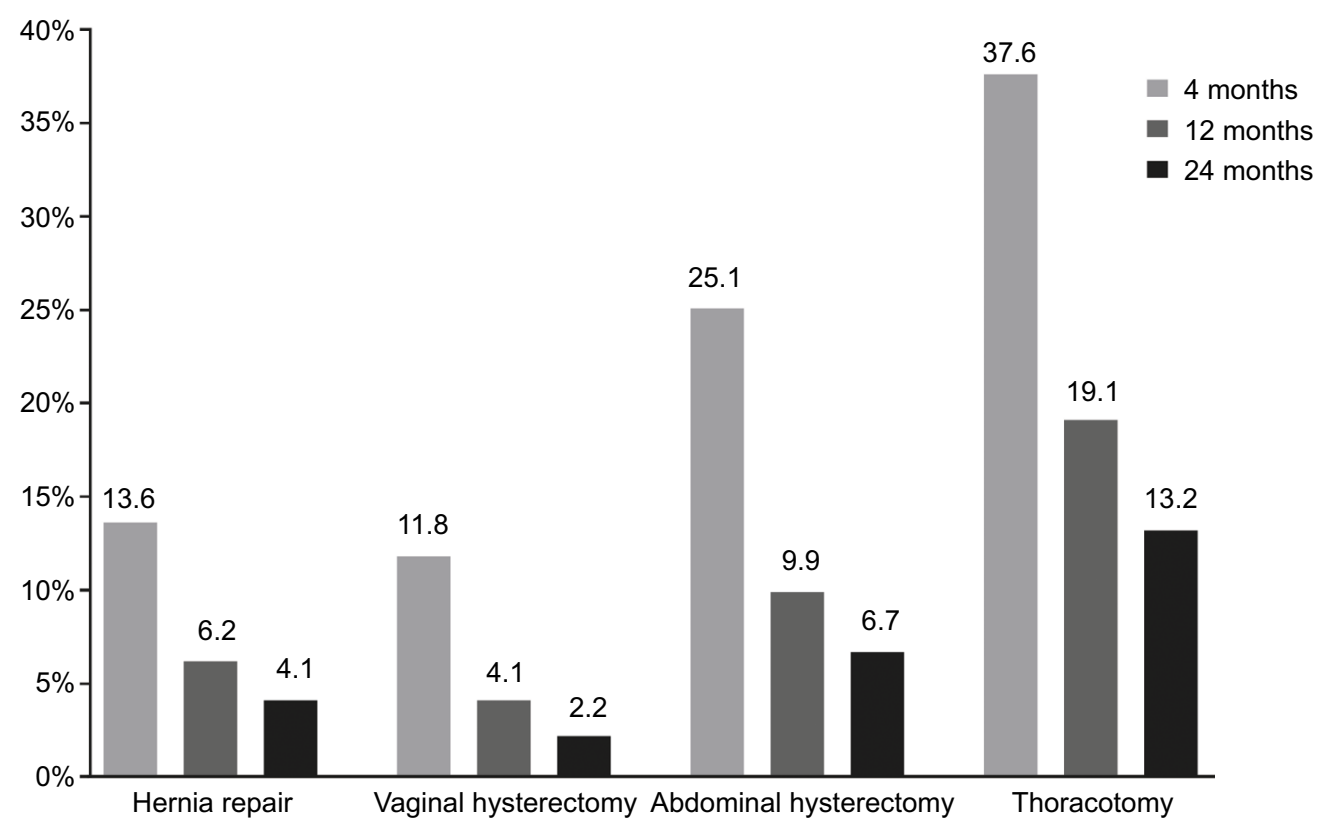

Figure 2 Incidence of chronic pain at 4, 12, and 24 months after surgery.

Note: Reprinted with permission from Montes A, Roca G, Sabate S, et al., Genetic and Clinical Factors Associated with Chronic Postsurgical Pain after Hernia Repair, Hysterectomy, and Thoracotomy: A Two-year Multicenter Cohort Study. Anesthesiology. I22(5): I I 23-4I. http://anesthesiology.pubs.asahq.org/Article.aspx?articleid=2 I 35 I 69.40

smoking, genetic predisposition, preexisting pain, psychological factors (eg, preoperative anxiety and depression), and duration of surgery. ${ }^{14,15,26,33,38,40,48,53-55,57,73,77-87}$

\section{Impaired function, recovery, and quality of life}

Postoperative pain also adversely affects physical functioning, recovery, and quality of life, ${ }^{54,55,88}$ and its impact is correlated with the severity of pain. ${ }^{18,55,88}$ Patients undergoing various types of elective surgery who had high levels of pain (pain score $\geq 40$ on a $100 \mathrm{~mm}$ visual analog scale) 4 days postprocedure were shown to be at risk 6 months later for increased functional limitations (odds ratio [OR] $1.87,95 \% \mathrm{CI}$ 1.02-3.41) $P=0.04$ ), poor global recovery (OR $2.61,95 \% \mathrm{CI}$ $1.47-4.62 ; P=0.001$ ), and impaired quality of life (aggregated Medical Outcomes Study Short-Form-36 [SF-36] quality of life score, standard $\beta=-0.169 ; P=0.001) .{ }^{55}$ Schulte et al found that physical function was worst at 3 months postthoracotomy, coinciding with peaks in pain scores at that time. ${ }^{89}$ Similarly, 6 months after thoracic surgery, lung cancer-surgery patients had significantly worse scores for physical functioning, role functioning - physical, social functioning, and mental health compared with presurgical scores, which was largely attributed to significantly worse pain scores postsurgery. ${ }^{90}$ In a large patient cohort, persistent pain occurring 3 months after thoracotomy was associated with significant reductions in physical functioning and vitality scores on the SF-36, even though the pain was reportedly mild in most patients. ${ }^{91}$

In a Spanish prospective cohort study, Montes et al found that chronic postsurgical pain interfered with daily activities in $18 \%$ of patients after hernia repair or abdominal hysterectomy, $27 \%$ after vaginal hysterectomy, and $31 \%$ after thoracotomy at the 4-month follow-up visit. ${ }^{40}$ In a similar Canadian study of chronic postoperative pain, nearly a third of patients described pain-related interference with sleep, mood, and enjoyment of life at even 6 months after gastrointestinal surgery. ${ }^{54} \mathrm{Six}$ weeks postoperatively, surgical patients had worse healthrelated quality of life than population norms in all domains measured, except mental health. Although improvement was observed by 6 months, quality of life in most domains, including physical function, general health, and vitality, remained significantly worse in the postsurgical pain cohort compared with norms. Postoperative pain was reported to affect activities of daily living adversely at 3 and 12 months postdischarge in approximately a quarter of patients who had had inpatient orthopedic surgery ${ }^{59}$ and at 1 year postprocedure in nearly a third of patients who had had outpatient knee arthroscopy. ${ }^{46}$ In an observational study of patients with chronic posttraumatic/postsurgical neuropathic pain, more severe pain was associated with significantly worse physical and mental health, general health status, and sleep outcomes, greater interference with function, and more depression and anxiety. ${ }^{92}$ 
Table I Summary of prospective clinical studies ( $\geq 50$ patients) in which acute pain was found to be a risk factor for the development of persistent postoperative pain

\begin{tabular}{|c|c|c|c|}
\hline Study & Surgical model & $\mathbf{n}$ & Findings \\
\hline Fletcher et $\mathrm{a}^{60}$ & I8 different surgery types & 3120 & 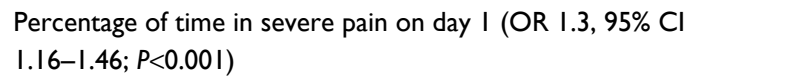 \\
\hline Hoofwijk et al ${ }^{46}$ & Outpatient surgery ( 10 specialties) & 908 & Acute postoperative pain (OR I.62, 95\% Cl I.02-2.58) \\
\hline Peters et $\mathrm{al}^{55}$ & $\begin{array}{l}\text { Elective surgery } \\
\text { (10 specialties) }\end{array}$ & 625 & $\begin{array}{l}\text { High level of acute pain (score } \geq 40 \text { on } 100 \mathrm{~mm} \text { VAS, OR } 3.21 \text {, } 95 \% \\
\text { Cl I.64-6.3; } P=0.00 \mathrm{I} \text { ) }\end{array}$ \\
\hline Choinière et $\mathrm{a}^{63}$ & Cardiac surgery & $\mathrm{I}, 247$ & $\begin{array}{l}\text { Moderate-severe acute pain on postoperative day } 3 \text { (adjusted OR } \\
2.67,95 \% \mathrm{Cl} I .74-4 . \mathrm{II} \text { ) }\end{array}$ \\
\hline van Gulik et al ${ }^{68}$ & Cardiac surgery via sternotomy & 146 & $\begin{array}{l}\text { Severe pain (NRS } \geq 4 \text { ) on postoperative day } 3 \text { (OR } 2.89,95 \% \mathrm{Cl} \\
\text { I.15-7.23, } P=0.02 \text { ) }\end{array}$ \\
\hline Setälä et al ${ }^{15}$ & Sternotomy & 100 & $\begin{array}{l}\text { High pain score on postoperative day I was the most significant } \\
\text { independent risk factor }(P<0.00 \text { I })\end{array}$ \\
\hline Niraj et al $\mathrm{l}^{75}$ & Thoracotomy & 306 & $\begin{array}{l}82 \% \text { of patients with } \geq 5 \text { episodes of severe pain within } 72 \text { hours of } \\
\text { surgery had persistent postsurgical pain at } 6 \text { months }\end{array}$ \\
\hline Hetmann et $\mathrm{al}^{\mid 61}$ & Thoracotomy & 106 & $\begin{array}{l}\text { Postoperative pain was significant in univariate analysis (OR I. } 43,95 \% \\
\text { CI I.05-1.95, } P=0.02 \text { ) }\end{array}$ \\
\hline Gotoda et $\mathrm{al}^{52}$ & Thoracotomy & 85 & $\begin{array}{l}\text { Pain on postsurgery day I (accounted for } 12.4 \% \text { of variance; } \\
P=0.0005 \text { ) }\end{array}$ \\
\hline Bisgaard et $\mathrm{al}^{71}$ & Laparoscopic cholecystectomy & 150 & Total and maximum pain during the first week $(P=0.005)$ \\
\hline Aasvang et $a^{69}$ & Herniotomy & 464 & 30-day postoperative pain intensity $(P=0.0002)$ \\
\hline Callesen et $\mathrm{al}^{72}$ & Groin-hernia repair & 466 & High cumulative pain scores I week after surgery $(P<0.05)$ \\
\hline Veal et $\mathrm{al}^{59}$ & Orthopedic surgery & 87 & $\begin{array}{l}\text { Average pain levels rated as moderate-severe at } 10 \text { days }(P=0.01) \\
\text { and } 6 \text { weeks }(P=0.02)\end{array}$ \\
\hline Sayers et $\mathrm{al}^{74}$ & Hip replacement & 321 & Acute postoperative pain at rest $(\beta=0.2, P<0.0002)$ \\
\hline Thomazeau et $\mathrm{a}^{57}$ & Knee replacement & 104 & High-intensity acute postoperative pain trajectory $(P=0.004)$ \\
\hline Lavand'homme et a ${ }^{64}$ & Knee arthroplasty & 112 & $\begin{array}{l}\text { Higher acute-pain scores for maximal pain for days } I-8 \text { ( } P<0.05 \text { at all } \\
\text { time points) }\end{array}$ \\
\hline Masselin-Dubois et $\mathrm{al}^{49}$ & $\begin{array}{l}\text { Total knee and hip arthroplasty and } \\
\text { breast surgery }\end{array}$ & 189 & Pain intensity on day $2(\mathrm{OR} 2.88,95 \% \mathrm{Cl}$ I.29-6.38; $P=0.009)$ \\
\hline Theunissen et $\mathrm{al}^{14}$ & Hysterectomy & 428 & Acute postsurgical pain on day $4(P<0.05)$ \\
\hline Pokkinen et al ${ }^{62}$ & Hysterectomy & 242 & $\begin{array}{l}\text { More severe pain in the first } 20 \text { postoperative hours was } \\
\text { associated with a higher likelihood of persistent pain } 6 \text { months after } \\
\text { hysterectomy }\end{array}$ \\
\hline Pinto et $\mathrm{al}^{67}$ & Hysterectomy & 186 & Acute postsurgical pain intensity at 48 hours $(P<0.001)$ \\
\hline Brandsborg et $\mathrm{a}^{45}$ & Hysterectomy & 90 & High acute postoperative pain intensity $(P=0.034)$ \\
\hline VanDenKerkof et al ${ }^{48}$ & Gynecologic & 433 & Moderate/severe in-hospital pain (RR 3,95\% Cl I-9.4) \\
\hline Wang et a ${ }^{38}$ & Breast cancer surgery & $\begin{array}{l}19,813 \\
\text { (30 studies) }\end{array}$ & 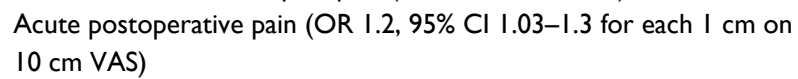 \\
\hline Andersen et $\mathrm{a}^{58}$ & Breast cancer surgery & 537 & Acute postoperative pain (OR $2.8, P=0.0018$ ) \\
\hline Bruce et $\mathrm{a}^{47}$ & Breast surgery & 362 & Acute postoperative pain at rest (OR I.34, $95 \% \mathrm{Cl} I .12-1.6 ; P=0.00 \mathrm{I})$ \\
\hline
\end{tabular}

Abbreviations: $\mathrm{Cl}$, confidence interval; OR, odds ratio; RR, relative risk; VAS, visual analog scale; NRS, numeric rating scale.

\section{Prolonged opioid use/opioid-induced adverse events}

Worse pain at the surgical site on the day of surgery has been reported to be a significant predictor of persistent opioid use over 6 months in patients undergoing total knee or hip arthroplasty. ${ }^{93}$ Using a large national-registry data set, Franklin et al found that greater pain reported 1 year after total-knee arthroplasty was associated with persistent opioid use 12 months postsurgery. ${ }^{94}$
Additionally, the consequences of poorly controlled pain during or after surgery may also include adverse effects of and toxicity related to anesthetic/analgesic medications, particularly if required for prolonged periods or at elevated doses to relieve pain. Although opioid analgesics remain the mainstay of postoperative pain therapy for efficacy, their use may be limited by potentially harmful effects. Common opioid-related AEs include respiratory depression, nausea, vomiting, pruritus, and bowel dysfunction, which have been 
associated with a substantial burden on quality of life. ${ }^{95-101}$ In addition, opioid-related AEs have an economic impact, as they have been shown to significantly increase hospital costs and length of stay. ${ }^{102}$

\section{Health economic impact}

Inadequate pain relief has been shown to result in increased length of stay, time to discharge, readmission rates, and time before ambulation, ${ }^{31,103-107}$ all of which can increase cost of care. ${ }^{104,108}$ In a retrospective analysis of same-day surgeries, Coley et al observed that pain was the predominant reason for unexpected hospital admission or readmission postprocedure, reported in $38 \%$ of patients who returned for care. ${ }^{104}$ The mean cost per patient for follow-up management of inadequately controlled pain after ambulatory surgery was estimated to be US $\$ 1,869 \pm \$ 4,553$ per visit (1999 dollars).

In 2008 in the US, the annual cost to society of common chronic-pain conditions, including postoperative pain, was conservatively estimated to be in the range of $\$ 560-\$ 635$ billion. ${ }^{12}$ These pain-related costs, which were based on health-care expenditure and lost productivity, were found to be higher than those related to heart disease, cancer, and diabetes. The cost of treating chronic pain that evolves from acute pain has been estimated to be as much as $\$ 1$ million per patient in a lifetime. ${ }^{108}$

\section{Improving postoperative pain: current and future options}

Progress has been made in the recognition of pain after surgery as an important public health problem and in the investigation of associated mechanisms and risk factors. However, relatively little evidence is available on interventions that prevent or minimize this common surgical complication and improve patient outcomes. Given that a complex combination of pathways appears to be involved, reducing the frequency and intensity of perioperative pain and minimizing its impact after surgery, including its progression to persistent pain, may require a multifaceted approach. Surgical techniques that diminish the risk of tissue or nerve injury and inflammation should be selected when possible. ${ }^{109}$ In addition, during the preoperative visit, identification of patients who may be prone to develop pain during or following surgery may allow for physical, emotional, and psychological preparations to mitigate surgical stress. ${ }^{110-112}$

Another fundamental strategy for pain prevention calls for more aggressive perioperative analgesic or anesthetic measures that decrease acute pain, minimizing noxious stimuli that induce peripheral and central sensitization. ${ }^{26,31,33,42,56,113-115}$
As reviewed elsewhere, ${ }^{7,42,116,117}$ the benefits of preventive interventions remain largely theoretical, as none has yet been shown definitively to influence the incidence or severity of postoperative pain. Some promising findings nonetheless warrant brief description in the following sections.

\section{Local and regional anesthesia}

Local anesthetics are frequently used during surgery as adjunctive therapy to manage acute pain and reduce analgesic consumption, but their effects on later postsurgical outcomes, including chronic postsurgical pain and quality of life, have been evaluated in a limited number of studies. ${ }^{6,116,118,119}$ In a small, randomized, controlled study, significantly fewer patients treated with intravenous lidocaine during breast cancer surgery reported persistent pain at 3-month follow-up than patients who received saline. ${ }^{5}$ However, evidence from several other studies assessing local anesthetics does not support their use as preventive therapy for chronic postoperative pain. ${ }^{120-126}$ Contradictory findings have also been reported with regard to the impact of perioperative administration of adjunctive lidocaine therapy on quality of life after surgery. In a randomized, controlled study, patients undergoing complex spine surgery who were included in a lidocaine group reported significantly better quality of life 1 month postoperatively than those in the placebo group. ${ }^{119}$ In contrast, in a similar study, spine-surgery patients who received lidocaine with intravenous anesthesia demonstrated no improvement in quality of life 1 month after surgery compared with those who received placebo. ${ }^{118}$

A Cochrane systematic review of 23 randomized, controlled trials compared the effects of local and regional anesthetics with those of conventional analgesia in preventing chronic postoperative pain. ${ }^{6}$ Pooled results favored epidural anesthesia after thoracotomy (OR $0.33,95 \%$ CI $0.2-0.56$ ) and paravertebral block after breast cancer surgery (OR $0.37,95 \%$ CI $0.14-0.94$ ) in reducing the risk of pain at 6 months. However, these data should be interpreted with caution, because of the small populations, methodological shortcomings, and incomplete outcome reporting of many of the included studies.

\section{Nonopioid analgesics}

Several classes of nonopioid pharmacological agents that target pain via differing pathways have been evaluated as means of improving postoperative outcomes, although the research remains limited. In three prospective, randomized trials, patients receiving the nonsteroidal anti-inflammatory drug (NSAID) ibuprofen or the COX2 inhibitor parecoxib 
did not achieve significant reduction in persistent pain after surgery. ${ }^{127-129}$ Based on a systematic review/meta-analysis of 14 randomized controlled trials of the uncompetitive $\mathrm{N}$-methyl-D-aspartate (NMDA)-receptor antagonist ketamine in various surgical models, Chaparro et al reported that treatment with this agent provided a significant but small decrease in the incidence of pain 3 months or more after surgery, although possible overestimation of treatment effect was noted because of the studies' small patient populations. ${ }^{\text {? }}$ However, researchers conducting two more recent systematic reviews concluded that available evidence did not support the effectiveness of perioperative administration of ketamine in reducing chronic pain after surgery. ${ }^{130,131}$ In a randomized, controlled pilot study of the preventive effects of ketamine on postmastectomy pain syndrome, when administered during surgery, this agent did not influence the incidence of persistent pain or quality of life for 3 months postsurgery. ${ }^{132}$

Similarly, although encouraging data from individual trials have been reported, systematic reviews of clinical trials of the 3-alkylated $\gamma$-aminobutyric acid analogs gabapentin and pregabalin have not consistently or unequivocally demonstrated reductions in the incidence or intensity of persistent postsurgical pain with these antiepileptic agents. . $^{716,130}$ However, in a small, randomized, controlled study, 3 months after major spine surgery, greater improvement in quality of life was reported by patients who received oral pregabalin versus placebo when administered 1 hour preoperatively and for 48 hours postoperatively, in addition to continuous infusion of morphine and ketorolac tromethamine. ${ }^{133}$ In addition, perioperative pregabalin was associated with improved functional outcomes 3 months postoperatively in patients who underwent spinal surgery under general anesthesia. ${ }^{134}$

The selective norepinephrine and serotonin-reuptake inhibitor venlafaxine has been shown significantly to reduce the incidence and intensity of pain 6 months after breast cancer surgery compared with placebo and gabapentin. ${ }^{135}$ Additionally, the perioperative administration of another antidepressant with this mechanism of action, duloxetine, as part of a multimodal regimen in women undergoing abdominal hysterectomy significantly improved postoperative quality of recovery. ${ }^{136}$ In a randomized, controlled study of patients undergoing coronary revascularization, administration of the selective serotonin-reuptake inhibitor escitalopram administered 2-3 weeks before surgery to 6 months after surgery provided more rapid improvement in mental health aspects of quality of life in all patients and reduced postoperative pain in patients who reported preoperative depression. ${ }^{137}$ Although promising, additional research is needed to determine the efficacy of antidepressants as preventive therapy postsurgery.

\section{Opioid analgesics}

Conventional opioids, such as morphine, hydrocodone, and fentanyl, continue to be considered the "gold standards" of postoperative pain management, largely because they are very effective analgesics that are available in a broad range of formulations. These agents nonetheless have well-recognized limitations, including a narrow therapeutic window, with a relatively small range of doses providing adequate pain relief without resulting in undesirable AEs or toxicity. Certain patient subgroups, including patients who are older, obese, smoke, or have sleep apnea, may be at particular risk of opioid-related respiratory depression and excessive sedation. The narrow therapeutic range of conventional opioids, which bind to $\mu$-opioid receptors, may be associated with their unselective activation of two intracellular signaling pathways: the G-protein pathway and the $\beta$-arrestin pathway. ${ }^{138}$ Preclinical studies have shown that G-protein pathway activation distal to the $\mu$-receptor results in analgesia; however, $\beta$-arrestin pathway activation is associated with opioid-related AEs, such as constipation and respiratory depression, as well as inhibition of G-protein-mediated analgesia. ${ }^{138-143}$

Three new opioids, which are currently in development, have a novel mechanism of action for relieving acute postoperative pain that is based on a differential signaling approach. These agents modulate $\mu$-receptor activity by selectively engaging intracellular pathways associated with analgesia ( $G$ protein) rather than those associated with adverse effects ( $\beta$-arrestin), thereby potentially improving the balance between pain control and tolerability. ${ }^{138}$ With a potentially expanded therapeutic window, these agents may more effectively relieve acute postoperative pain and reduce the consequences of poorly controlled pain, including its progression to chronic postoperative pain.

PZM21, a selective $\mu$-opioid-receptor agonist, has been shown potently to activate G-protein pathway signaling, with minimal $\beta$-arrestin 2 recruitment. ${ }^{9}$ In preclinical studies, G-protein-mediated action of PZM 21 on $\mu$-receptor activity provided analgesia with an improved AE profile (eg, reduced constipation and respiratory depression) compared with morphine at equianalgesic doses; no activity was observed on reflexive pain responses mediated through the spinal cord. Mitragynine pseudoindoxyl, an oxidative rearrangement product of the corynanthe alkaloid mitragynine (isolated from the Southeast Asian plant Mitragyna speciosa), is a $\mu$-opioid- 
receptor agonist and $\delta$-receptor antagonist with differential signaling properties. ${ }^{8}$ In preclinical studies, mitragynine had high affinity at the $\mu$-receptor and produced analgesia; it did not recruit $\beta$-arrestin and resulted in minimal respiratory depression and less constipation than morphine.

Oliceridine (TRV130) is a novel $\mu$-receptor G-protein pathway-selective modulator that differentially activates G-protein coupling while limiting $\beta$-arrestin recruitment. ${ }^{144,145}$ In Phase II clinical studies conducted in patients with moderate-severe acute pain after bunionectomy or abdominoplasty, oliceridine administered in either fixed or flexible (as needed) doses provided significantly greater reductions in pain scores than placebo and similar but more rapid analgesia than morphine. ${ }^{10,11}$ In the abdominoplasty study, oliceridine-treated patients reported no serious AEs and had fewer opioid-related AEs, such as nausea, vomiting, and respiratory depression, than morphine-treated patients. ${ }^{11}$ Although findings from studies of these novel opioid analgesics are also encouraging, additional research is needed to examine whether they improve patient outcomes, such as quality of life, or prevent the evolution to chronic pain because they potentially provide more effective control of acute postoperative pain.

\section{Multimodal analgesia}

Since this concept's introduction in $1993,{ }^{146}$ the combined use of local and regional anesthetics, different classes of nonopioid pharmacologic agents, such as NSAIDs, COX2 inhibitors, NMDA-receptor antagonists, and antiepileptics, and opioid analgesics, has become a widely accepted means of reducing acute postoperative pain while limiting perioperative opioid consumption and opioid-related AEs. Insufficient research is available, but some individual clinical trials have demonstrated a decreased incidence of chronic postoperative pain when multimodal regimens are used to manage pain during surgery. ${ }^{116,147-150}$ Given the increased use of multimodal approaches over the past two decades, future studies clearly must address their effects beyond opioid sparing in reducing early postsurgical pain and its consequences.

\section{Conclusion}

Postoperative pain continues to be inadequately managed in a surprising proportion of patients, and is associated with numerous negative clinical, patient-reported, and health economic outcomes. Importantly, poorly controlled acute pain after surgery has been consistently shown to be a predictive factor for the development of chronic pain. More effective analgesic/anesthetic perioperative measures may help prevent the adverse consequences of poorly controlled pain, including its transition to persistent pain. Preliminary evidence from studies of local and regional anesthetics, nonopioid analgesics, such as NSAIDs, COX2 inhibitors, NMDA-receptor antagonists, and antiepileptic and antidepressant agents, suggests potential benefit, but is inconsistent and insufficiently robust to prompt a modified approach. Conventional opioid therapies remain the mainstay of postoperative pain management, but opioid analgesic use involves the challenging pursuit of an acceptable balance between effective pain control and harmful side effects. Pain control with conventional opioids can be suboptimal, due to a narrow therapeutic window, which may be associated with their unselective mechanism of action. New selective $\mu$-opioid agonists, such as PZM21 and oliceridine, which have differential $\mu$-receptor downstream signaling compared with conventional opioids, may help to optimize acute-pain management by providing a wider therapeutic window, allowing for potent analgesia with fewer safety and tolerability concerns. Large-scale, well-controlled studies are needed to determine if currently available treatment approaches, including multimodal regimens or novel therapies, such as selective $\mu$-opioid-receptor agonists, used during surgery or prior to discharge reduce the negative impact of inadequate pain relief.

\section{Acknowledgments}

Medical writing support was provided by Kevin Wang of Xelay Acumen (San Mateo, CA, USA) and Donna McGuire of Engage Scientific Solutions (Philadelphia, PA, USA), funded by Trevena Inc (Upper Merion, PA, USA).

\section{Disclosure}

TJG has received honoraria from Trevena Inc, and was not compensated for his role in the development of this paper. The author reports no other conflicts of interests in this work.

\section{References}

1. Meara JG, Leather AJ, Hagander L, et al. Global Surgery 2030: evidence and solutions for achieving health, welfare, and economic development. Lancet. 2015;386(9993):569-624.

2. Weiser TG, Haynes AB, Molina G, et al. Size and distribution of the global volume of surgery in 2012. Bull World Health Organ. 2016;94(3): 201-209F.

3. Buie VC, Owings MF, DeFrances CJ, Golosinskiy A. National hospital discharge survey: 2006 annual summary. Vital Health Stat 13. 2010;(168):1-79.

4. Hall MJ, Schwartzman A, Zhang J, Liu X. Ambulatory surgery data from hospitals and ambulatory surgery centers: United States, 2010. Natl Health Stat Report. 2017;(102):1-15.

5. Grigoras A, Lee P, Sattar F, Shorten G. Perioperative intravenous lidocaine decreases the incidence of persistent pain after breast surgery. Clin J Pain. 2012;28(7):567-572. 
6. Andreae MH, Andreae DA. Local anaesthetics and regional anaesthesia for preventing chronic pain after surgery. Cochrane Database Syst Rev. 2012;10:CD007105.

7. Chaparro LE, Smith SA, Moore RA, Wiffen PJ, Gilron I. Pharmacotherapy for the prevention of chronic pain after surgery in adults. Cochrane Database Syst Rev. 2013;(7):CD008307.

8. Váradi A, Marrone GF, Palmer TC, et al. Mitragynine/corynantheidine pseudoindoxyls as opioid analgesics with $\mu$-agonism and $\delta$-antagonism, which do not recruit $\beta$-arrestin-2. J Med Chem. 2016;59(18):8381-8397.

9. Manglik A, Lin H, Aryal DK, et al. Structure-based discovery of opioid analgesics with reduced side effects. Nature. 2016;537(7619):185-190.

10. Viscusi ER, Webster L, Kuss M, et al. A randomized, phase 2 study investigating TRV130, a biased ligand of the $\mu$-opioid receptor, for the intravenous treatment of acute pain. Pain. 2016;157(1):264-272.

11. Singla N, Minkowitz HS, Soergel DG, Burt D, Skobieranda F. A randomized, phase IIB study investigating oliceridine (TRV130), a novel $\mu$ receptor $\mathrm{G}$ protein pathway selective ( $\mu$-GPS) modulator. Poster presented at: 41st Annual Regional Anesthesiology and Acute Pain Medicine Meeting; March 31-April 2, 2016; New Orleans, LA.

12. Institute of Medicine. Relieving Pain in America: A Blueprint for Transforming Prevention, Care, Education, and Research. Washington: National Academies Press; 2011.

13. Gan TJ, Habib AS, Miller TE, White W, Apfelbaum JL. Incidence, patient satisfaction, and perceptions of post-surgical pain: results from a US national survey. Curr Med Res Opin. 2014;30(1):149-160.

14. Theunissen M, Peters ML, Schepers J, et al. Recovery 3 and 12 months after hysterectomy: epidemiology and predictors of chronic pain, physical functioning, and global surgical recovery. Medicine (Baltimore) 2016;95(26):e3980.

15. Setälä P, Kalliomäki ML, Järvelä K, Huhtala H, Sisto T, Puolakka P. Postoperative hyperalgesia does not predict persistent post-sternotomy pain: observational study based on clinical examination. Acta Anaesthesiol Scand. 2015;60(4):520-528.

16. Apfelbaum JL, Chen C, Mehta SS, Gan TJ. Postoperative pain experience: results from a national survey suggest postoperative pain continues to be undermanaged. Anesth Analg. 2003;97(2):534-540.

17. Sommer M, de Rijke JM, van Kleef M, et al. The prevalence of postoperative pain in a sample of 1490 surgical inpatients. Eur J Anaesthesiol 2008;25(4):267-274.

18. Chan EY, Blyth FM, Nairn L, Fransen M. Acute postoperative pain following hospital discharge after total knee arthroplasty. Osteoarthritis Cartilage. 2013;21(9):1257-1263.

19. Gerbershagen HJ, Aduckathil S, van Wijck AJ, Peelen LM, Kalkman CJ, Meissner W. Pain intensity on the first day after surgery: a prospective cohort study comparing 179 surgical procedures. Anesthesiology. 2013;118(4):934-944.

20. Dolin SJ, Cashman JN, Bland JM. Effectiveness of acute postoperative pain management - I: evidence from published data. Br J Anaesth 2002;89(3):409-423.

21. Munafo MR, Stevenson J. Anxiety and surgical recovery: reinterpreting the literature. J Psychosom Res. 2001;51(4):589-596.

22. Caumo W, Schmidt AP, Schneider CN, et al. Preoperative predictors of moderate to intense acute postoperative pain in patients undergoing abdominal surgery. Acta Anaesthesiol Scand. 2002;46(10):1265-1271.

23. Kalkman CJ, Visser K, Moen J, Bonsel GJ, Grobbee DE, Moons KG. Preoperative prediction of severe postoperative pain. Pain. 2003;105(3):415-423.

24. Pavlin DJ, Sullivan MJ, Freund PR, Roesen K. Catastrophizing: a risk factor for postsurgical pain. Clin J Pain. 2005;21(1):83-90.

25. Granot M, Ferber SG. The roles of pain catastrophizing and anxiety in the prediction of postoperative pain intensity: a prospective study. Clin J Pain. 2005;21(5):439-445.

26. Grosu I, de Kock M. New concepts in acute pain management: strategies to prevent chronic postsurgical pain, opioid-induced hyperalgesia, and outcome measures. Anesthesiol Clin. 2011;29(2):311-327.
27. Aubrun F, Valade N, Coriat P, Riou B. Predictive factors of severe postoperative pain in the postanesthesia care unit. Anesth Analg. 2008;106(5): 1535-1541.

28. Ip HY, Abrishami A, Peng PW, Wong J, Chung F. Predictors of postoperative pain and analgesic consumption: a qualitative systematic review. Anesthesiology. 2009;111(3):657-677.

29. Breivik H. Postoperative pain management: why is it difficult to show that it improves outcome? Eur J Anaesthesiol. 1998;15(6):748-751.

30. Carr DB, Goudas LC. Acute pain. Lancet. 1999;353(9169):2051-2058.

31. Joshi GP, Ogunnaike BO. Consequences of inadequate postoperative pain relief and chronic persistent postoperative pain. Anesthesiol Clin North America. 2005;23(1):21-36.

32. Kehlet H. Multimodal approach to control postoperative pathophysiology and rehabilitation. Br J Anaesth. 1997;78(5):606-617.

33. Kehlet H, Jensen TS, Woolf CJ. Persistent postsurgical pain: risk factors and prevention. Lancet. 2006;367(9522):1618-1625.

34. Macrae WA. Chronic pain after surgery. Br JAnaesth. 2001;87(1):88-98.

35. Poobalan AS, Bruce J, Smith WC, King PM, Krukowski ZH, Chambers WA. A review of chronic pain after inguinal herniorrhaphy. Clin $J$ Pain. 2003;19(1):48-54.

36. Johansen A, Romundstad L, Nielsen CS, Schirmer H, Stubhaug A. Persistent postsurgical pain in a general population: prevalence and predictors in the Tromsø study. Pain. 2012;153(7):1390-1396.

37. Wildgaard K, Ravn J, Kehlet H. Chronic post-thoracotomy pain: a critical review of pathogenic mechanisms and strategies for prevention. Eur J Cardiothorac Surg. 2009;36(1):170-180.

38. Wang L, Guyatt GH, Kennedy SA, et al. Predictors of persistent pain after breast cancer surgery: a systematic review and meta-analysis of observational studies. CMAJ. 2016;188:E352-E361.

39. Macrae WA. Chronic post-surgical pain: 10 years on. Br J Anaesth. 2008;101(1):77-86.

40. Montes A, Roca G, Sabate S, et al. Genetic and clinical factors associated with chronic postsurgical pain after hernia repair, hysterectomy, and thoracotomy: a two-year multicenter cohort study. Anesthesiology. 2015;122(5):1123-1141.

41. Dualé C, Ouchchane L, Schoeffler P. Neuropathic aspects of persistent postsurgical pain: a French multicenter survey with a 6-month prospective follow-up. J Pain. 2014;15(1):24 e21-e24.e20.

42. Badiola IJ. Can chronic pain be prevented? Anesthesiol Clin. 2016;34(2): 303-315.

43. Reddi D, Curran N. Chronic pain after surgery: pathophysiology, risk factors and prevention. Postgrad Med J. 2014;90(1062):222-227.

44. Wilder-Smith OH, Schreyer T, Scheffer GJ, Arendt-Nielsen L. Patients with chronic pain after abdominal surgery show less preoperative endogenous pain inhibition and more postoperative hyperalgesia: a pilot study. J Pain Palliat Care Pharmacother. 2010;24(2):119-128.

45. Brandsborg B, Dueholm M, Nikolajsen L, Kehlet H, Jensen TS. A prospective study of risk factors for pain persisting 4 months after hysterectomy. Clin J Pain. 2009;25(4):263-268.

46. Hoofwijk DM, Fiddelers AA, Peters ML, et al. Prevalence and predictive factors of chronic postsurgical pain and poor global recovery 1 year after outpatient surgery. Clin J Pain. 2015;31(12):1017-1025.

47. Bruce J, Thornton AJ, Powell R, et al. Psychological, surgical, and sociodemographic predictors of pain outcomes after breast cancer surgery: a population-based cohort study. Pain. 2014;155(2):232-243.

48. VanDenKerkhof EG, Hopman WM, Goldstein DH, et al. Impact of perioperative pain intensity, pain qualities, and opioid use on chronic pain after surgery: a prospective cohort study. Reg Anesth Pain Med. 2012;37(1):19-27.

49. Masselin-Dubois A, Attal N, Fletcher D, et al. Are psychological predictors of chronic postsurgical pain dependent on the surgical model? A comparison of total knee arthroplasty and breast surgery for cancer. J Pain. 2013;14(8):854-864.

50. Baratta JL, Schwenk ES, Viscusi ER. Clinical consequences of inadequate pain relief: barriers to optimal pain management. Plast Reconstr Surg. 2014;134(4 Suppl 2):15S-21S. 
51. Katz J, Jackson M, Kavanagh BP, Sandler AN. Acute pain after thoracic surgery predicts long-term post-thoracotomy pain. Clin J Pain. 1996;12(1):50-55

52. Gotoda Y, Kambara N, Sakai T, Kishi Y, Kodama K, Koyama T. The morbidity, time course and predictive factors for persistent postthoracotomy pain. Eur J Pain. 2001;5(1):89-96.

53. Perkins FM, Kehlet H. Chronic pain as an outcome of surgery: a review of predictive factors. Anesthesiology. 2000;93(4):1123-1133.

54. VanDenKerkhof EG, Hopman WM, Reitsma ML, et al. Chronic pain, healthcare utilization, and quality of life following gastrointestinal surgery. Can J Anaesth. 2012;59(7):670-680.

55. Peters ML, Sommer M, de Rijke JM, et al. Somatic and psychologic predictors of long-term unfavorable outcome after surgical intervention. Ann Surg. 2007;245(3):487-494.

56. Wu CL, Raja SN. Treatment of acute postoperative pain. Lancet. 2011;377(9784):2215-2225.

57. Thomazeau J, Rouquette A, Martinez V, et al. Predictive factors of chronic post-surgical pain at 6 months following knee replacement: influence of postoperative pain trajectory and genetics. Pain Physician. 2016;19(5):E729-E741.

58. Andersen KG, Duriaud HM, Jensen HE, Kroman N, Kehlet H. Predictive factors for the development of persistent pain after breast cancer surgery. Pain. 2015;156(12):2413-2422.

59. Veal FC, Bereznicki LR, Thompson AJ, Peterson GM, Orlikowski C. Subacute pain as a predictor of long-term pain following orthopedic surgery: an Australian prospective 12 month observational cohort study. Medicine (Baltimore). 2015;94(36):e1498.

60. Fletcher D, Stamer UM, Pogatzki-Zahn E, et al. Chronic postsurgical pain in Europe: an observational study. Eur J Anaesthesiol. 2015;32(10):725-734.

61. Hetmann F, Kongsgaard UE, Sandvik L, Schou-Bredal I. Prevalence and predictors of persistent post-surgical pain 12 months after thoracotomy. Acta Anaesthesiol Scand. 2015;59(6):740-748.

62. Pokkinen SM, Nieminen K, Yli-Hankala A, Kalliomäki ML. Persistent posthysterectomy pain: a prospective, observational study. Eur J Anaesthesiol. 2015;32(10):718-724.

63. Choinière M, Watt-Watson J, Victor JC, et al. Prevalence of and risk factors for persistent postoperative nonanginal pain after cardiac surgery: a 2-year prospective multicentre study. CMAJ. 2014;186(7):E213-E223.

64. Lavand'homme PM, Grosu I, France MN, Thienpont E. Pain trajectories identify patients at risk of persistent pain after knee arthroplasty: an observational study. Clin Orthop Relat Res. 2014;472(5):1409-1415.

65. Pinto PR, McIntyre T, Ferrero R, Almeida A, Araujo-Soares V. Risk factors for moderate and severe persistent pain in patients undergoing total knee and hip arthroplasty: a prospective predictive study. PLoS One. 2013;8(9):e73917.

66. De Oliveira GS Jr, Chang R, Khan SA, et al. Factors associated with the development of chronic pain after surgery for breast cancer: a prospective cohort from a tertiary center in the United States. Breast J. 2014;20(1):9-14

67. Pinto PR, McIntyre T, Nogueira-Silva C, Almeida A, Araujo-Soares $\mathrm{V}$. Risk factors for persistent postsurgical pain in women undergoing hysterectomy due to benign causes: a prospective predictive study. J Pain. 2012;13(11):1045-1057.

68. van Gulik L, Janssen LI, Ahlers SJ, et al. Risk factors for chronic thoracic pain after cardiac surgery via sternotomy. Eur J Cardiothorac Surg. 2011;40(6):1309-1313.

69. Aasvang EK, Gmaehle E, Hansen JB, et al. Predictive risk factors for persistent postherniotomy pain. Anesthesiology. 2010;112(4):957-969.

70. Poleshuck EL, Katz J, Andrus CH, et al. Risk factors for chronic pain following breast cancer surgery: a prospective study. J Pain. 2006;7(9): 626-634.

71. Bisgaard T, Rosenberg J, Kehlet H. From acute to chronic pain after laparoscopic cholecystectomy: a prospective follow-up analysis. Scand J Gastroenterol. 2005;40(11):1358-1364.

72. Callesen T, Bech K, Kehlet H. Prospective study of chronic pain after groin hernia repair. Br J Surg. 1999;86(12):1528-1531.
73. Boogaard S, Heymans MW, de Vet HC, et al. Predictors of persistent neuropathic pain: a systematic review. Pain Physician. 2015;18(5): 433-457.

74. Sayers A, Wylde V, Lenguerrand E, et al. Rest pain and movementevoked pain as unique constructs in hip and knee replacements. Arthritis Care Res (Hoboken). 2016;68(2):237-245.

75. Niraj G, Kelkar A, Kaushik V, et al. Audit of postoperative pain management after open thoracotomy and the incidence of chronic postthoracotomy pain in more than 500 patients at a tertiary center. J Clin Anesth. 2017;36:174-177.

76. Clarke H, Kay J, Mitsakakis N, Katz J. Acute pain after total hip arthroplasty does not predict the development of chronic postsurgical pain 6 months later. $J$ Anesth. 2010;24(4):537-543.

77. Bruce J, Drury N, Poobalan AS, Jeffrey RR, Smith WC, Chambers WA. The prevalence of chronic chest and leg pain following cardiac surgery: a historical cohort study. Pain. 2003;104(1-2):265-273.

78. Smith WC, Bourne D, Squair J, Phillips DO, Chambers WA. A retrospective cohort study of post mastectomy pain syndrome. Pain. 1999;83(1):91-95.

79. Poobalan AS, Bruce J, King PM, Chambers WA, Krukowski ZH, Smith WC. Chronic pain and quality of life following open inguinal hernia repair. Br J Surg. 2001;88(8):1122-1126.

80. Hannan EL, Magaziner J, Wang JJ, et al. Mortality and locomotion 6 months after hospitalization for hip fracture: risk factors and riskadjusted hospital outcomes. JAMA. 2001;285(21):2736-2742.

81. Orbell S, Johnston M, Rowley D, Davey P, Espley A. Self-efficacy and goal importance in the prediction of physical disability in people following hospitalization: a prospective study. Br J Health Psychol. 2001;6(Pt 1):25-40.

82. Thomazeau J, Rouquette A, Martinez V, et al. Acute pain factors predictive of post-operative pain and opioid requirement in multimodal analgesia following knee replacement. Eur J Pain. 2016;20(5):822-832.

83. Lewis GN, Rice DA, McNair PJ, Kluger M. Predictors of persistent pain after total knee arthroplasty: a systematic review and metaanalysis. Br J Anaesth. 2015;114(4):551-561.

84. Andersen KG, Kehlet H. Persistent pain after breast cancer treatment: a critical review of risk factors and strategies for prevention. J Pain. 2011;12(7):725-746.

85. Gärtner R, Jensen MB, Nielsen J, Ewertz M, Kroman N, Kehlet H. Prevalence of and factors associated with persistent pain following breast cancer surgery. JAMA. 2009;302(18):1985-1992.

86. Hinrichs-Rocker A, Schulz K, Järvinen I, Lefering R, Simanski C, Neugebauer EA. Psychosocial predictors and correlates for chronic post-surgical pain (CPSP): a systematic review. Eur J Pain. 2009;13(7):719-730.

87. Singh JA, Lewallen D. Age, gender, obesity, and depression are associated with patient-related pain and function outcome after revision total hip arthroplasty. Clin Rheumatol. 2009;28(12):1419-1430.

88. Wu CL, Naqibuddin M, Rowlingson AJ, Lietman SA, Jermyn RM, Fleisher LA. The effect of pain on health-related quality of life in the immediate postoperative period. Anesth Analg. 2003;97(4):1078-1085.

89. Schulte T, Schniewind B, Dohrmann P, Küchler T, Kurdow R. The extent of lung parenchyma resection significantly impacts long-term quality of life in patients with non-small cell lung cancer. Chest. 2009;135(2):322-329.

90. Handy JR Jr, Asaph JW, Skokan L, et al. What happens to patients undergoing lung cancer surgery? Outcomes and quality of life before and after surgery. Chest. 2002;122(1):21-30.

91. Kinney MA, Hooten WM, Cassivi SD, et al. Chronic postthoracotomy pain and health-related quality of life. Ann Thorac Surg. 2012;93(4):1242-1247.

92. Parsons B, Schaefer C, Mann R, et al. Economic and humanistic burden of post-trauma and post-surgical neuropathic pain among adults in the United States. J Pain Res. 2013;6:459-469.

93. Goesling J, Moser SE, Zaidi B, et al. Trends and predictors of opioid use following total knee and total hip arthroplasty. Pain. 2016;157(6):1259-1265. 
94. Franklin PD, Karbassi JA, Li W, Yang W, Ayers DC. Reduction in narcotic use after primary total knee arthroplasty and association with patient pain relief and satisfaction. J Arthroplasty. 2010;25(6 Suppl):12-16.

95. Dahan A, Aarts L, Smith TW. Incidence, reversal, and prevention of opioid-induced respiratory depression. Anesthesiology. 2010;112(1): 226-238.

96. Barletta JF, Asgeirsson T, Senagore AJ. Influence of intravenous opioid dose on postoperative ileus. Ann Pharmacother. 2011;45(7-8): 916-923.

97. Goettsch WG, Sukel MP, van der Peet DL, van Riemsdijk MM, Herings RM. In-hospital use of opioids increases rate of coded postoperative paralytic ileus. Pharmacoepidemiol Drug Saf. 2007;16(6):668-674.

98. Smith HS, Laufer A. Opioid induced nausea and vomiting. Eur $J$ Pharmacol. 2014;722:67-78.

99. Bell TJ, Panchal SJ, Miaskowski C, Bolge SC, Milanova T, Williamson R. The prevalence, severity, and impact of opioid-induced bowel dysfunction: results of a US and European Patient Survey (PROBE 1). Pain Med. 2009;10(1):35-42.

100. Dorn S, Lembo A, Cremonini F. Opioid-induced bowel dysfunction: epidemiology, pathophysiology, diagnosis, and initial therapeutic approach. Am J Gastroenterol Suppl. 2014;2(1):31-37.

101. Benson JL, Campbell HE, Phillips CN. Opioid-induced pruritus. Consult Pharm. 2015;30(4):221-227.

102. Oderda GM, Said Q, Evans RS, et al. Opioid-related adverse drug events in surgical hospitalizations: impact on costs and length of stay. Ann Pharmacother. 2007;41(3):400-406.

103. Robinson KP, Wagstaff KJ, Sanghera S, Kerry RM. Postoperative pain following primary lower limb arthroplasty and enhanced recovery pathway. Ann R Coll Surg Engl. 2014;96(4):302-306.

104. Coley KC, Williams BA, DaPos SV, Chen C, Smith RB. Retrospective evaluation of unanticipated admissions and readmissions after same day surgery and associated costs. J Clin Anesth. 2002;14(5):349-353.

105. Jones NL, Edmonds L, Ghosh S, Klein AA. A review of enhanced recovery for thoracic anaesthesia and surgery. Anaesthesia. 2013;68(2):179-189.

106. Twersky R, Fishman D, Homel P. What happens after discharge? Return hospital visits after ambulatory surgery. Anesth Analg. 1997;84(2):319-324.

107. Morrison RS, Magaziner J, McLaughlin MA, et al. The impact of post-operative pain on outcomes following hip fracture. Pain. 2003;103(3):303-311.

108. Cousins MJ, Power I, Smith G. 1996 Labat lecture - pain: a persistent problem. Reg Anesth Pain Med. 2000;25(1):6-21.

109. Aasvang E, Kehlet H. Chronic postoperative pain: the case of inguinal herniorrhaphy. Br J Anaesth. 2005;95(1):69-76.

110. Yarnitsky D, Crispel Y, Eisenberg E, et al. Prediction of chronic postoperative pain: pre-operative DNIC testing identifies patients at risk. Pain. 2008;138(1):22-28.

111. Minnella EM, Bousquet-Dion G, Awasthi R, Scheede-Bergdahl C, Carli F. Multimodal prehabilitation improves functional capacity before and after colorectal surgery for cancer: a five-year research experience. Acta Oncol. 2017;56(2):295-300.

112. Joshi GP, Schug SA, Kehlet H. Procedure-specific pain management and outcome strategies. Best Pract Res Clin Anaesthesiol. 2014;28(2):191-201.

113. Dahl JB, Kehlet H. Preventive analgesia. Curr Opin Anaesthesiol. 2011;24(3):331-338.

114. Woolf CJ. Central sensitization: implications for the diagnosis and treatment of pain. Pain. 2011;152(3 Suppl):S2-S15.

115. Katz J, Seltzer Z. Transition from acute to chronic postsurgical pain: risk factors and protective factors. Expert Rev Neurother. 2009;9(5):723-744.

116. Clarke H, Poon M, Weinrib A, Katznelson R, Wentlandt K, Katz J. Preventive analgesia and novel strategies for the prevention of chronic post-surgical pain. Drugs. 2015;75(4):339-351.
117. Rawal N. Current issues in postoperative pain management. Eur $J$ Anaesthesiol. 2016;33(3):160-171.

118. Dewinter G, Moens P, Fieuws S, Vanaudenaerde B, Van de Velde M, Rex S. Systemic lidocaine fails to improve postoperative morphine consumption, postoperative recovery and quality of life in patients undergoing posterior spinal arthrodesis: a double-blind, randomized, placebo-controlled trial. Br J Anaesth. 2017;118(4):576-585.

119. Farag E, Ghobrial M, Sessler DI, et al. Effect of perioperative intravenous lidocaine administration on pain, opioid consumption, and quality of life after complex spine surgery. Anesthesiology. 2013;119(4):932-940.

120. Fassoulaki A, Sarantopoulos C, Melemeni A, Hogan Q. Regional block and mexiletine: the effect on pain after cancer breast surgery. Reg Anesth Pain Med. 2001;26(3):223-228.

121. Fassoulaki A, Patris K, Sarantopoulos C, Hogan Q. The analgesic effect of gabapentin and mexiletine after breast surgery for cancer. Anesth Analg. 2002;95(4):985-991.

122. Albi-Feldzer A, Mouret-Fourme EE, Hamouda S, et al. A double-blind randomized trial of wound and intercostal space infiltration with ropivacaine during breast cancer surgery: effects on chronic postoperative pain. Anesthesiology. 2013;118(2):318-326.

123. Merivirta R, Aarimaa V, Aantaa R, et al. Postoperative fentanyl patch versus subacromial bupivacaine infusion in arthroscopic shoulder surgery. Arthroscopy. 2013;29(7):1129-1134.

124. Onan B, Onan IS, Kilickan L, Sanisoglu I. Effects of epidural anesthesia on acute and chronic pain after coronary artery bypass grafting. J Card Surg. 2013;28(3):248-253.

125. Williams D, Petruccelli D, Paul J, Piccirillo L, Winemaker M, de Beer J. Continuous infusion of bupivacaine following total knee arthroplasty: a randomized control trial pilot study. J Arthroplasty. 2013;28(3):479-484.

126. Corsini T, Cuvillon P, Forgeot A, Chapelle C, Seffert P, Chauleur C. [Single-dose intraincisional levobupivacaine infiltration in caesarean postoperative analgesia: a placebo-controlled double-blind randomized trial]. Ann Fr Anesth Reanim. 2013;32(1):25-30. French.

127. Fransen M, Anderson C, Douglas J, et al. Safety and efficacy of routine postoperative ibuprofen for pain and disability related to ectopic bone formation after hip replacement surgery (HIPAID): randomised controlled trial. BMJ. 2006;333(7567):519.

128. Lakdja F, Dixmérias F, Bussieères E, Fonrouge JM, Lobéra A. [Preventive analgesic effect of intraoperative administration of ibuprofen-arginine on postmastectomy pain syndrome]. Bull Cancer. 1997;84(3):259-263. French.

129. Romundstad L, Breivik H, Roald H, Skolleborg K, Romundstad PR, Stubhaug A. Chronic pain and sensory changes after augmentation mammoplasty: long term effects of preincisional administration of methylprednisolone. Pain. 2006;124(1-2):92-99.

130. Humble SR, Dalton AJ, Li L. A systematic review of therapeutic interventions to reduce acute and chronic post-surgical pain after amputation, thoracotomy or mastectomy. Eur J Pain. 2015;19(4): $451-465$

131. Klatt E, Zumbrunn T, Bandschapp O, Girard T, Ruppen W. Intra- and postoperative intravenous ketamine does not prevent chronic pain: a systematic review and meta-analysis. Scand J Pain. 2015;7:42-54

132. Crousier M, Cognet V, Khaled M, Gueugniaud PY, Piriou V. [Effect of ketamine on prevention of postmastectomy chronic pain: a pilot study]. Ann Fr Anesth Reanim. 2008;27(12):987-993. French.

133. Gianesello L, Pavoni V, Barboni E, Galeotti I, Nella A. Perioperative pregabalin for postoperative pain control and quality of life after major spinal surgery. J Neurosurg Anesthesiol. 2012;24(2): 121-126.

134. Khurana G, Jindal P, Sharma JP, Bansal KK. Postoperative pain and long-term functional outcome after administration of gabapentin and pregabalin in patients undergoing spinal surgery. Spine (Phila Pa 1976). 2014;39(6):E363-E368. 
135. Amr YM, Yousef AA. Evaluation of efficacy of the perioperative administration of venlafaxine or gabapentin on acute and chronic postmastectomy pain. Clin J Pain. 2010;26(5):381-385.

136. Castro-Alves LJ, de Medeiros AC, Neves SP, et al. Perioperative duloxetine to improve postoperative recovery after abdominal hysterectomy: a prospective, randomized, double-blinded, placebo-controlled study. Anesth Analg. 2016;122(1):98-104.

137. Chocron S, Vandel P, Durst C, et al. Antidepressant therapy in patients undergoing coronary artery bypass grafting: the MOTIV-CABG trial. Ann Thorac Surg. 2013;95(5):1609-1618.

138. Violin JD, Crombie AL, Soergel DG, Lark MW. Biased ligands at G-protein-coupled receptors: promise and progress. Trends Pharmacol Sci. 2014;35(7):308-316.

139. Bohn LM, Dykstra LA, Lefkowitz RJ, Caron MG, Barak LS. Relative opioid efficacy is determined by the complements of the G protein-coupled receptor desensitization machinery. Mol Pharmacol. 2004;66(1):106-112.

140. Bohn LM, Lefkowitz RJ, Gainetdinov RR, Peppel K, Caron MG, Lin FT. Enhanced morphine analgesia in mice lacking $\beta$-arrestin 2. Science. 1999;286(5449):2495-2498.

141. DeWire SM, Ahn S, Lefkowitz RJ, Shenoy SK. $\beta$-Arrestins and cell signaling. Annu Rev Physiol. 2007;69:483-510.

142. Raehal KM, Bohn LM. Mu opioid receptor regulation and opiate responsiveness. AAPS J. 2005;7(3):E587-E591.

143. Raehal KM, Walker JK, Bohn LM. Morphine side effects in $\beta$-arrestin 2 knockout mice. J Pharmacol Exp Ther. 2005;314(3): 1195-1201.
144. Chen XT, Pitis P, Liu G, et al. Structure-activity relationships and discovery of a $G$ protein biased $\mu$ opioid receptor ligand, [(3-methoxythiophen-2-yl)methyl](\{2-[(9R)-9-(pyridin-2-yl)-6-oxaspiro-[4.5] decan-9-yl]ethyl $\}$ )amine (TRV130), for the treatment of acute severe pain. J Med Chem. 2013;56(20):8019-8031.

145. DeWire SM, Yamashita DS, Rominger DH, et al. A G protein-biased ligand at the $\mu$-opioid receptor is potently analgesic with reduced gastrointestinal and respiratory dysfunction compared with morphine. J Pharmacol Exp Ther. 2013;344(3):708-717.

146. Kehlet H, Dahl JB. The value of "multimodal" or "balanced analgesia" in postoperative pain treatment. Anesth Analg. 1993;77(5):1048-1056.

147. Fassoulaki A, Triga A, Melemeni A, Sarantopoulos C. Multimodal analgesia with gabapentin and local anesthetics prevents acute and chronic pain after breast surgery for cancer. Anesth Analg. 2005;101(5): 1427-1432.

148. Buvanendran A, Kroin JS, Tuman KJ, et al. Effects of perioperative administration of a selective cyclooxygenase 2 inhibitor on pain management and recovery of function after knee replacement: a randomized controlled trial. JAMA. 2003;290(18):2411-2418.

149. Buvanendran A, Kroin JS, Della Valle CJ, Kari M, Moric M, Tuman KJ. Perioperative oral pregabalin reduces chronic pain after total knee arthroplasty: a prospective, randomized, controlled trial. Anesth Analg. 2010;110(1):199-207.

150. Lavand'homme P, De Kock M, Waterloos H. Intraoperative epidural analgesia combined with ketamine provides effective preventive analgesia in patients undergoing major digestive surgery. Anesthesiology. 2005;103(4):813-820.
Journal of Pain Research

\section{Publish your work in this journal}

The Journal of Pain Research is an international, peer reviewed, open access, online journal that welcomes laboratory and clinical findings in the fields of pain research and the prevention and management of pain. Original research, reviews, symposium reports, hypothesis formation and commentaries are all considered for publication.

\section{Dovepress}

The manuscript management system is completely online and includes a very quick and fair peer-review system, which is all easy to use. Visit http://www.dovepress.com/testimonials.php to read real quotes from published authors. 